\title{
IDENTIFIKASI DAN KARAKTERISASI POLA KOKOK PADA AYAM PELIHARA BERDASARKAN PENDEKATAN BIOAKUSTIK
}

\section{(Identification and Characterization of Crowing Pattern on Domestic Chickens Through Bioacoustic Approach)}

\author{
Andika Verdian Ginting1, Hamdan ${ }^{2}$ dan Tri Hesti Wahyuni \\ 1. Mahasiswa Program Studi Peternakan Fakultas Pertanian Universitas SumateraUtara \\ 2. Staf Pengajar Program Studi Peternakan Fakultas Pertanian Universitas Sumatera Utara
}

\begin{abstract}
The aim of this study is to obtain data for the basic characteristics of the crowing sound, crowing sound analysis and bioacoustic patterns of the domestic chicken. The experiment was conducted in Ai Martubung Farm Village Martubung on June to September 2014. This study used 11 types of the adult Roosters Bangkok, Burma, Junglefowl, Kampung, Kate, Serama, Bagon, Magon, Saigon and Suratani chicken where each type is consisting of 2 head. Data were analyzed by Applications Sound Forge Xp 10. Parameters measured were number of syllables crowing, crowing duration, wave frequency and frequency of crowing. The results showed that the Kampung chicken had the longest duration of crowing of (3,659 seconds) while the Shortest crowing is Magon (1,326 seconds). The results of the analysis for the number of syllables crowing showed that 10 types of chicken has 4 syllables crowing and 1 type has 3 syllables, namely Suratani. The results of the analysis for frequency sound Wavelength Serama chicken crowing had the highest frequency of $2747.5 \mathrm{~Hz}$ and lowest of $916 \mathrm{~Hz}$, namely Pakhoi. It is concluded that each type of chicken has a different sound and distinctive crowing.
\end{abstract}

Keywords: Roosters, bioacoustic patterns, frequency sound, Sound Forge XP 10

\begin{abstract}
ABSTRAK
Penelitian ini bertujuan untuk memperoleh data dasar karakteristik suara kokok, analisis suara kokok dan pola bioakustik pada kokok ayam. Penelitian dilaksanakan di Ai Martubung Farm Kelurahan Martubung Bulan Juni sampai dengan September 2014. Penelitian menggunakan 11 jenis Ayam Jantan dewasa yaitu Ayam Bangkok, Birma, Hutan, Kampung, Kate, Serama, Bagon, Magon, Saigon dan Suratani dengan masing-masing jenis terdiri dari 2 ekor. Analisis data penelitian menggunakan Aplikasi Sound Forge Xp 10. Paramater yang diamati adalah jumlah suku kata kokok, durasi kokok, frekuensi gelombang dan frekuensi berkokok. Hasil penelitian menunjukkan bahwa ayam kampung memiliki durasi kokok terpanjang dengan durasi kokok selama 3,659 detik dan durasi yang tercepat adalah pada ayam Magon dengan durasi kokok selama 1,326 detik. Hasil analisis untuk jumlah suku kata kokok menunjukkan bahwa ada 10 jenis ayam yang memiliki 4 suku kata kokok dan 1 jenis ayam yang memiliki 3 suku kata yaitu ayam Suratani. Hasil analisis suara untuk frekuensi panjang gelombang kokok yaitu Ayam Serama memiliki frekuensi tertinggi sebesar 2747,5 Hz dan yang terendah pada ayam Pakhoi sebesar $916 \mathrm{~Hz}$. Kesimpulannya adalah bahwa setiap jenis ayam memiliki suara kokok yang berbeda dan memiliki ciri yang khas.
\end{abstract}

Kata kunci : Ayam jantan, pola bioakustik, frekuensi kok, Sound Forge xp 10 


\section{PENDAHULUAN}

Ayam pelihara merupakan ayam hasil domestikasi dari ayam liar menjadi ayam yang dijinakkan dan dipelihara. Ayam pelihara di Indonesia ada yang diproduksi masyarakat untuk petelur dan pedaging namun ada juga beberapa bangsa ayam dipelihara untuk kesenangan atau hobi. Ayam tersebut dipelihara untuk kesenangan manusia seperti menimakti kemerduan suara, keunikan bentuk tubuhnya untuk menghilangkan stress dan menyalurkan hobi.

Di Indonesia, saat ini, suara telah menjadi komoditas ekonomi. Berdasarkan tipenya ada dua jenis suara pada bangsa unggas, yaitu call (suara panggilan) dan song (suara nyanyian). Tipe suara call digunakan dalam berkomunikasi antar sesama, sebagai isyarat adanya musuh (respon predator) atau adanya gangguan, saat terkejut dan ketika menemukan makanan. Tipe suara song merupakan tipe suara sebagai pernyataan wilayah kekuasaan (territorial declare) dan sebagai atraksi memikat unggas betina yang akan dikawini. Tipe suara call terdapat pada unggas jantan dan betina, sedangkan tipe song hanya pada unggas jantan. Selain itu, suara dijadikan sebagai indikator kesejahteraan hewan, ekspresi emosional dan status fisiologi hewan.

Suara dapat pula dijadikan sebagai penanda individu, karena setiap individu mempunyai karakteristik suara spesifik. Tidak satupun orang atau hewan yang mempunyai suara persis sama, perbedaan frekuensi dan amplitudo, baik antar individu maupun antar spesies. Suara kokok pada ayam jantan merupakan salah satu potensi yang bernilai ekonomi. Ayam jantan yang memiliki suara kokok merdu biasanya memiliki nilai jual yang tinggi. Sebagai contoh Ayam Kokok Balenggek (AKB) yang menang kontes memiliki harga 50 kali lebih tinggi dari ayam jantan yang berkokok tidak merdu( Rusfidra, 2004).

Perekaman suara kokok ayam dilakukan untuk mengetahui ciri dari ayam tipe song atau tipe call. Sound forge pro 10 atau sound forge pro 11 merupakan suatu perangkat lunak komputer yang digunakan untuk memproses dan menganalisa suara dan biasanya digunakan untuk proses penyuntingan musik.

Oleh karena itu untuk mengetahui ciri khas dari setiap suara kokok dari berbagai bangsa ayam maka dilakukannya analisis tentang suara kokok dari setiap bangsa ayam tersebut dan mengetahui makna dari suara kokok tersebut. 


\section{BAHAN DAN METODE PENELITIAN}

\section{Lokasi dan Waktu Penelitian}

Penelitian ini dilaksanakan di Kelurahan Martubung Kecamatan Medan Labuhan. Penelitian ini dilaksanakan dari Mei sampai Juni 2014.

\section{Bahan dan Alat}

\section{Bahan}

Ayam yang digunakan dalam penelitian ini berjumlah sebelas bangsa ayam yaitu ayam Kampung, ayam Bangkok, ayam Birma, ayam Serama, ayam Kate, ayam Magon, ayam Hutan, ayam Bagon, ayam Suratani, ayam Pakhoi, ayam Saigon yang masing-masing 2 ekor per bangsa dengan total 22 ekor.

\section{Alat}

Alat yang digunakan adalah:

1. Sangkar ayam individu

2. Baterai 2 Set,

3. Satu set alat perekam Sony ICD-PX333M

Keterangan Sony ICD-PX333M : Perekam suara digital ini telah dilengkapi dengan teknologi Intelligent Noise Cut untuk mengurangi suara bising yang terdapat di sekitar objek saat sedang melakukan perekaman. Track Mark akan membantu memberi tanda saat melakukan perekaman untuk memudahkan menemukan suatu sesi. Perekam suara ini dilengkapi dengan slot memori eksternal dan klip mic. Dengan kualitas 128 kbps, speaker output $300 \mathrm{~mW}$ serta dilengkapi dengan teknologi untuk mengurangi suara bising, hasil rekaman akan terdengar jernih. Sony ICD-PX333M perekam suara digital menggunakan kapasitas memori 4 GB. Perekam suara ini dapat merekam hingga 178 jam dengan waktu standby hingga 72 jam.

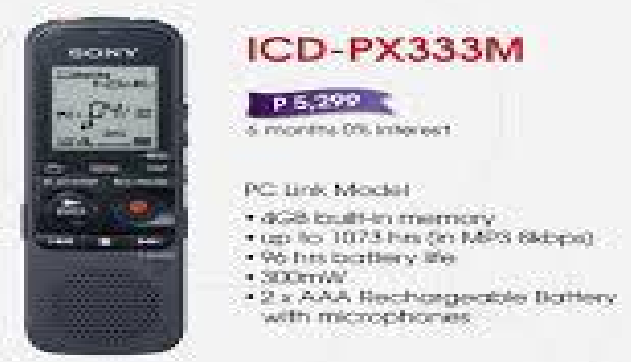

Gambar 1. Alat Perekam Sony ICD-PX333M 
4. Sebuah laptop yang dilengkapi dengan aplikasi program analisis suara Sound Forge xp 10 Keterangan Sound Forge Xp 10 : Sound Forge xp adalah salah satu produk audio dari perusahaan sony. Sound forge $x p$ berfungsi untuk pemotongan audio, menyambung audio, memberi efek audio, membesarkan volume, compressing audio, editing equalizer, dan converting format audio. Analisis suara kokok dengan memanfaatkan berbagai perangkat lunak sound forge xp 10 dan spectrogram 6,4 dapat membantu proses penjurian pada kontes ayam Gaga'. Dengan melakukan analisis suara kokok dan menvisualisasikannya, maka proses penjurian dapat dilakukan secara objektif, transparan, terukur, dapat diulang, dan tingkat tingkat akurasi yang baik. Visualisasi suara kokok ditampilkan dalam bentuk waveform berupa suara kokok dalam bentuk grafik. Sumbu X adalah dimensi waktu (detik) dan sumbu $\mathrm{Y}$ adalah dimensi frekuensi $(\mathrm{kHz})$. Waveform berguna untuk menggambarkan pola kokok (Anderson, 2010).

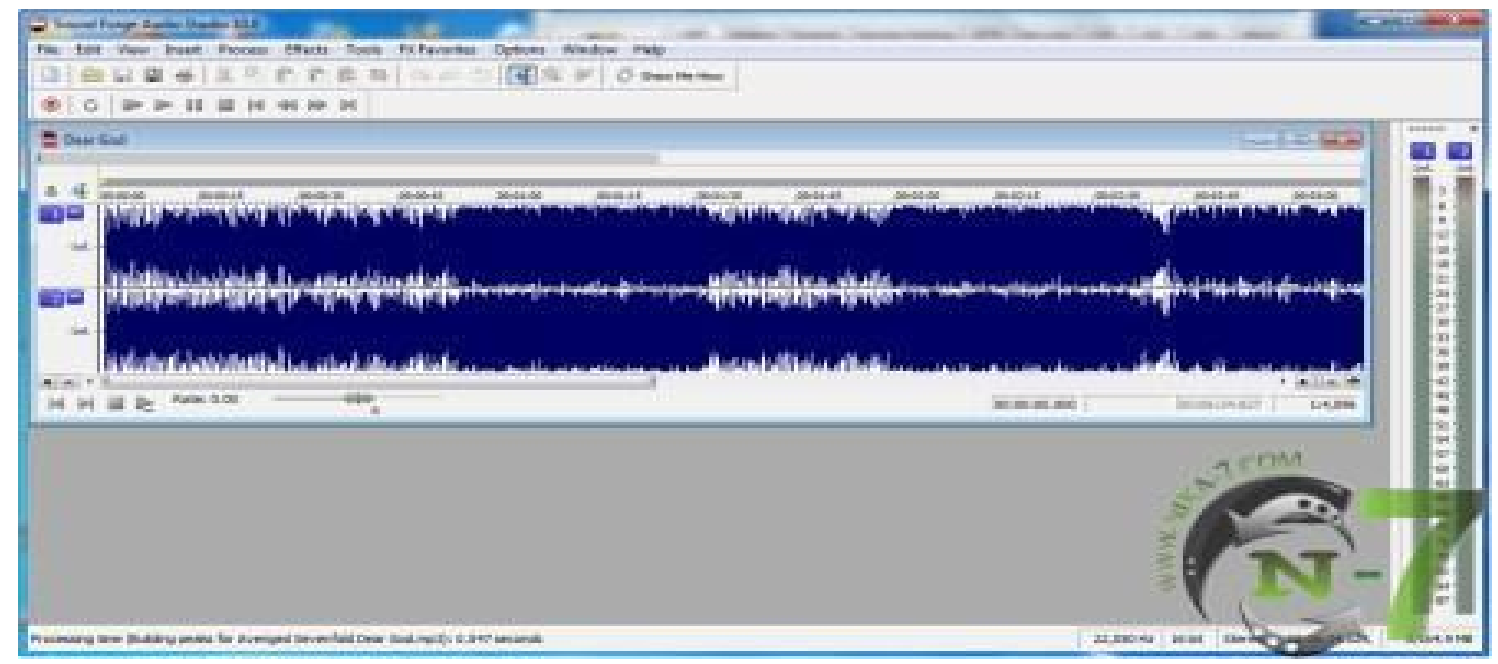

Gambar 2. Tampilan Sound Forge Xp 10

\section{Metode Penelitian}

Penelitian ini dilakukan dengan beberapa tahap diantaranya :

\section{Persiapan Ayam Penelitian}

Ayam yang digunakan sebanyak sebelas Bangsa Ayam yaitu Ayam kampung, Ayam Bangkok, Ayam Birma, Ayam Serama, Ayam Kate, Ayam Magon, Ayam Hutan, Ayam Bagon, Ayam Pakhoi, Ayam Suratani, Ayam Saigon dan dibagi dua yaitu untuk Parameter jumlah suku kata kokok, durasi kokok, dan panjang gelombang kokok menggunakan kesebelas bangsa ayam tersebut sedangkan untuk parameter frekuensi berkokok menggunakan enam jenis bangsa ayam yaitu Ayam Kampung, Ayam Bangkok, Ayam Birma, Ayam Serama, Ayam Kate dan Ayam Hutan. 
2. Analisis Suara Kokok

a. Kegiatan merekam suara kokok dengan alat perekam suara

b. Perekaman Suara kokok dilakukan selama 2 jam

3. Melakukan digitalisasi rekaman suara kokok ke komputer menggunakan program Sound forge xp 10.

4. Analisis suara kokok untuk visualisasi, gelombang suara, durasi kokok, dan frekuensi kokok.

5. Interpretasi hasil analisis suara kokok.

\section{Parameter Penelitian}

1. Jumlah Suku kata kokok

a. Jumlah suku kata kokok gelombang ke- 1 adalah suara kokok yang merapat antara suku kata ku dengan suku kata ku berikutnya dari suara kokok gelombang ke-1.

b. Jumlah suku kata kokok pada gelombang ke- 2 adalah total suku kata suara kokok setelah kokok gelombang ke-1 hingga kokok berakhir.

2. Durasi Kokok

a. Durasi kokok gelombang ke-1 adalah lama waktu berkokok (detik) yang dihasilkan dari suara kokok pada gelombang ke-1.

b. Durasi kokok gelombang ke- 2 adalah lama waktu berkokok (detik) yang dihasilkan dari suara kokok pada gelombang ke-2.

3. Frekuensi Gelombang Kokok

Panjang gelombang kokok adalah alur gelombang kokok (heartz) yang dihasilkan dari suara kokok.

4. Frekuensi Berkokok

Frekuensi berkokok yaitu jumlah ayam berkokok dalam 1 gelombang waktu.

\section{Pelaksanaan Penelitian}

1. Persiapan Tempat Penelitian

Tempat penelitian dibuat dengan sangkar individu dan diletakkan didalam ruangan kosong yang kedap suara dan dhadapkan ke arah jendela. Hal ini dibuat untuk mempermudah perekaman suara kokok ayam agar tidak bercampur dengan suara lain.

2. Pemilihan Ternak

Ayam yang dipilih adalah ayam yang telah dewasa atau yang sudah berkokok. Ayam yang dipilih adalah ayam yang sehat dan tidak stres.

3. Perekaman Suara 
Perekaman suara dilakukan dengan cara meletakkan alat perekam disebelah sangkar individu agar perekaman suara kokok dapat direkam dengan baik dan diharapkan dapat menghasilkan rekaman suara kokok yang baik. Perekaman suara dilakukan selama 2 jam Per ekor dan direkam pada pagi hari sesuai dengan pernyataan Rusfidra (2005) yang menyatakan bahwa ayam paling sering berkokok yaitu pada saat pagi hari .

4. Analisis Suara

Hasil perekaman suara kokok ayam tersebut lalu diolah dalam aplikasi Sound Forge xp 10. Hasil perekaman tersebut akan diubah dalam bentuk wave form.

\section{Pengumpulan Data}

1. Data berupa hasil rekaman suara dari alat rekaman kemudian dimasukkan Kedalam komputer untuk diolah melalui Software Sound Forge xp 10 dengan menampilkan gambar wave form.

2. Analisis data yang didapat pada penelitian ini dianalisis secara deskriptif, dihitung nilai rataannya (Sudjana, 2005)

\section{HASIL DAN PEMBAHASAN}

\section{Karakteristik Suara Kokok berbagai Jenis Ayam}

Suara kokok berbagai jenis ayam memiliki ciri khas masing-masing jenis ayam tersebut ada yang tipe song dan ada tipe call. Suara kokok tipe call adalah suara kokok untuk berinteraksi dengan sesama ayam lainnya sedangkan tipe song merupakan suara kokok untuk mendominasi wilayah kekuasaan dan untuk memikat betina untuk dikawini. Suara kokok ayam tipe song memiliki ciri tersendiri tergantung dari jenis ayam jantan tersebut. Seperti ayam Bangkok yang memiliki suara kokok yang kuat dan pendek http://ayam-bangkokcom.blogspot.com (2014), ayam kampung yang memiliki suara kokok yang khas yaitu merdu dan unik berbeda jelas dengan ayam Bangkok dan berbagai jenis ayam lainnya memiliki keunikan suara kokok masing-masing.

Suara kokok ayam yang bagus adalah ketika ayam tersebut sudah dewasa atau ketika ayam jantan tersebut sudah dapat kawin Fredde (1976). Suara kokok ayam tipe song biasanya terjadi pada waktu pagi, siang, sore dan malam Zymmerman (1995). Namun jika ingin mendengar suara kokok tipe song yang terbaik kita dapat mendengarnya pada pagi hari. Pita suara atau bagian jakun bawah pada batang tenggorok (percabangan bronki menjadi dua) ini menghasilakan suara pada unggas. Pita suara merupakan satu-satunya bagian alat pernapasan 
yang mampu menghasilkan suara, sedangkan jakun merupakan bagian pembentuk suara bagi ayam jantan (Oliver 1966).

Tabel 1. Hasil perhitungan analisis suara dari berbagai jenis ayam pelihara

\begin{tabular}{ccccccc}
\hline No & Jenis Ayam & $\begin{array}{c}\text { Jumlah } \\
\text { suku kata } \\
\text { gelombang } \\
\text { 1 }\end{array}$ & $\begin{array}{c}\text { Jumlah } \\
\text { suku kata } \\
\text { gelombang }\end{array}$ & $\begin{array}{c}\text { Durasi } \\
\text { kokok } \\
\text { gelombang } \\
\text { 1(detik) }\end{array}$ & $\begin{array}{c}\text { Durasi } \\
\text { kokok } \\
\text { gelombang } \\
\text { 2(detik) }\end{array}$ & $\begin{array}{c}\text { Frekuensi } \\
\text { gelombang } \\
\text { kokok } \\
\text { (hertz) }\end{array}$ \\
\hline 1 & Bangkok & 4,00 & 4,00 & 3,501 & 3,551 & 937,50 \\
2 & Birma & 4.00 & 4,00 & 3,242 & 3,488 & 1110,00 \\
3 & Hutan & 4,00 & 4,00 & 3,098 & 2,952 & 1229,00 \\
4 & Kampung & 4,00 & 4,00 & 3,609 & 3,709 & 1154,00 \\
5 & Kate & 4,00 & 4,00 & 3,479 & 3,214 & 2435,50 \\
6 & Serama & 4,00 & 4,00 & 2,986 & 3,010 & 2747,50 \\
7 & Bagon & 4,00 & 4,00 & 1,433 & 1,411 & 948,50 \\
8 & Magon & 4,00 & 4,00 & 1,514 & 1,469 & 1336,00 \\
9 & Pakhoi & 4,00 & 4,00 & 1,629 & 1,371 & 916,00 \\
10 & Saigon & 4,00 & 4,00 & 1,631 & 1,764 & 1056,00 \\
11 & Suratani & 3,00 & 3,50 & 1,431 & 1,737 & 1013,00 \\
\hline
\end{tabular}

\section{Jumlah Suku Kata Kokok}

Jumlah suku kata kokok adalah suara kokok yang berkelompok dan menghasilkan suara kokok. Suku kata kokok adalah bunyi suara seperti "kuk-kuk-kuk-kuk" yang rapat dan berirama merdu menghasilkan suara dengan nada yang berbeda. Dari hasil analisis suara kokok yang telah dilakukan pada Tabel 1 dapat dilihat jumlah suku kata kokok yang dihasilkan dari sebelas jenis ayam yang berbeda. Dari sebelas jenis ayam yang telah dianalisis terdapat sepuluh jenis ayam dengan jumlah suku kata kokok yang sama yaitu dengan jumlah suku kata kokok empat dan satu jenis berbeda yaitu jenis ayam suratani dengan jumlah suku kata kokok adalah tiga.

\section{a. Jumlah suku kata kokok gelombang 1}

Jumlah suku kata kokok gelombang ke-1 adalah suara kokok yang merapat antara suku kata "kuk" dengan kata "kuk" berikutnya dari suara kokok gelombang pertama. Pada ke-sebelas jenis ayam yang telah dianalisis terdapat sepuluh jenis yang memiliki jumlah suku kata empat. Hasil penelitian tentang suku kata kokok gelombang satu juga sudah diteliti oleh Rusfrida (2004) dan Junaidi (2012) tetapi jenis ayam yang digunakan adalah ayam Balenggek dan ayam Gaga. Hasilnya melaporkan bahwa ayam Gaga memiliki suku kata pada gelombang ke-satu adalah sebanyak dua suku kata sedangkan pada ayam Balenggek terdapat 
jumlah suku kata sebanyak tiga suku kata terdiri dari kokok depan dan belakang (Rusfidra ,2004).

Berikut adalah contoh wave form dari analisis suara jumlah suku kata kokok gelombang 1 dari jenis ayam Bangkok

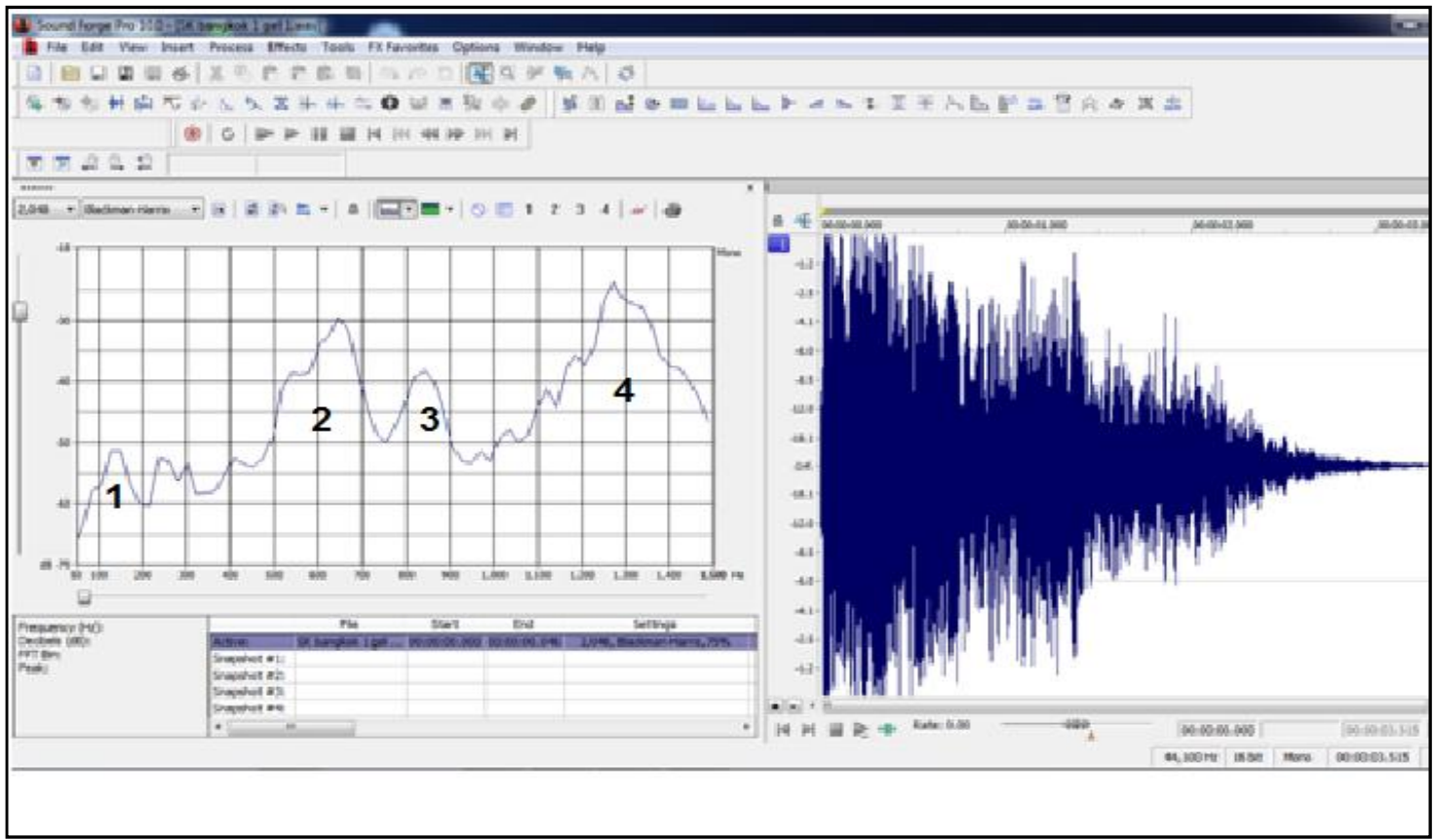

Gambar 3. Wave Form jumlah suku kata kokok Ayam Bangkok

Keterangan Gambar :

1. Angka 1 merupakan awalan suara kata "kuk" yang pertama

2. Angka 2 dan 3 merupakan suara "kuk" yang berada ditengah

3. Angka 4 merupakan suara "kuk" yang berada diakhir dari kokok ayam

\section{b. Jumlah suku kata kokok gelombang 2}

Jumlah suku kata kokok gelombang kedua adalah jumlah suara kata "kuk" yang merapat dari awal kokok sampai ayam berhenti berkokok. Dari hasil analisis yang telah dilakukan didapatkan jumlah suku kata kokok gelombang kedua pada sebelas jenis ayam, yaitu sepuluh jenis ayam memiliki jumlah suku kata kokok adalah empat suku kata dan satu jenis ayam yaitu ayam suratani hanya memiliki suku kata kokok tiga. Hasil penelitian tentang suku kata kokok gelombang dua juga sudah diteliti oleh Rusfidra (2004) dan Junaidi (2012) tetapi jenis ayam yang digunakan adalah ayam Balenggek dan ayam Gaga. Hasilnya melaporkan bahwa ayam gaga memiliki jumlah suku kata pada gelombang kedua adalah 18,4 
suku kata dan ayam balenggek memiliki Sembilan belas suku kata pada gelombang kedua.(Rusfidra,2004 dan Junaidi, 2012).

\section{Durasi Kokok}

Dari hasil analisis suara ayam yang telah dilakukan dapat dilihat pada Tabel 1. Dari ke-sebelas jenis ayam yang telah dianalisis didapat enam jenis ayam yaitu ayam Bangkok, Birma, Hutan, Kampung, Serama dan Kate memiliki durasi kokok diatas 2,8 detik lebih lama dari ayam buras yaitu 2,28 detik (Nurningsih, 2010). Namun 5 jenis ayam lainnya yaitu ayam Bagon, Magon, Suratani, Saigon dan Pakhoi memiliki durasi kokok yang lebih cepat dari ayam buras yaitu dibawah dua detik. Selain itu, dari semua ayam yang telah dianalisis ternyata masih sangat jauh berbeda dengan ayam gaga tipe dangdut kelas panjang yang mampu berkokok selama 30,83 detik (Junaidi, 2012) dan berbeda dengan ayam Toutenko Toumaru dan Koeyoshi dari jepang yang mampu berkokok dengan rataan 15 detik (Tsudzuki, 2003).

\section{a. Durasi kokok gelombang 1}

Durasi kokok gelombang pertama merupakan awalan kokok ayam atau pertama kali ayam mulai berkokok. Dari Tabel 1 dapat dilihat bahwa durasi kokok ayam gelombang 1 memiliki durasi paling panjang yaitu ayam kampung dengan rata-rata durasi kokok yaitu 3,609 detik dan ayam yang memiliki durasi kokok paling singkat adalah ayam Suratani dengan rata-rata durasi kokok yaitu 1,431 detik.

\section{b. Durasi Kokok Gelombang 2}

Durasi kokok gelombang 2 adalah lama atau durasi kokok ayam setelah gelombang 1. Dari tabel 1 dapat dilihat bahwa durasi kokok gelombang ke 2 memiliki durasi paling panjang yaitu ayam kampung dengan rata-rata durasi yaitu 3,709 detik dan ayam dengan durasi paling singkat adalah ayam Pakhoi dengan rata-rata durasi kokok yaitu 1,371 detik.

\section{Frekuensi Gelombang Kokok}

Frekuensi gelombang kokok adalah bunyi atau frekuensi yang dikeluarkan dari kokok ayam yang nilainya dalam satuan hertz $(\mathrm{Hz})$ dalam sekali berkokok. Dari hasil analisa suara yang dilakukan dapat kita lihat pada Tabel 1 bahwa ayam memiliki variasi nilai frekuensi. Ayam yang memiliki frekuensi tertinggi yaitu ayam Serama yang memiliki frekuensi 2747,5 $\mathrm{Hz}$ dan ayam yang memiliki frekuensi terendah adalah ayam Pakhoi dengan frekuensi 916 
Hz. Hasil analisa tersebut merupakan frekuensi dari perhitungan sekali berkokok. Bunyi suara kokok yang dihasilkan ayam dapat didengar manusia dengan jelas karena memiliki frekuensi paling rendah yaitu 916 Hz. Hal ini sesuai dengan pernyataan Rukmini (2000) yang menyatakan kemampuan manusia normal untuk mendengar suara terkecil mulai dari frekuensi $20 \mathrm{~Hz}$ sampai dengan $20.000 \mathrm{~Hz}$.

\section{Frekuensi Berkokok}

Frekuensi berkokok adalah jumlah kokok yang dihasilkan ayam dalam 1 periode waktu. Pada Tabel 2 dapat dilihat jumlah kokok ayam dalam 2 periode waktu. Jenis ayam yang diambil adalah Ayam Bangkok, Ayam Birma, Ayam Hutan, Ayam Kate, Ayam Serama, dan Ayam Kampung.

Tabel 2. Frekuensi Berkokok dan Durasi Jarak antara periode 1 dan periode 2

\begin{tabular}{ccccccc}
\hline No & Nama Ayam & $\begin{array}{c}\text { Jumlah } \\
\text { Kokok } \\
\text { Periode 1 }\end{array}$ & $\begin{array}{c}\text { Jumlah } \\
\text { Kokok } \\
\text { Periode 2 }\end{array}$ & $\begin{array}{c}\text { Durasi } \\
\text { Kokok } \\
\text { Periode 1 } \\
\text { (Menit) }\end{array}$ & $\begin{array}{c}\text { Durasi } \\
\text { Kokok } \\
\text { Periode 2 } \\
\text { (menit) }\end{array}$ & $\begin{array}{c}\text { Jarak Kokok } \\
\text { periode 1-2 } \\
\text { (Menit) }\end{array}$ \\
\hline 1 & Bangkok & 9,50 & 13,50 & $1.82 .942,00$ & $3.03 .902,00$ & $17.09 .479,00$ \\
2 & Birma & 10,50 & 12,50 & $3.34 .831,00$ & $3.29 .517,00$ & $24,31.112,00$ \\
3 & Hutan & 6,50 & 5,00 & $2.12 .616,00$ & $1.33 .362,00$ & $58.32 .373,00$ \\
4 & Kate & 12,50 & 8,00 & $3.18 .951,00$ & $2.28 .790,00$ & $42.29 .876,00$ \\
5 & Serama & 10,50 & 11,00 & $2.23 .851,00$ & $3.28 .468,00$ & $27.21 .403,00$ \\
6 & Kampung & 17,00 & 11,50 & $4.33 .711,00$ & $4.25 .156,00$ & $23.39 .947,00$ \\
\hline
\end{tabular}

Hasil Tabel 2 dapat dilihat bahwa ayam Kampung memiliki jumlah kokok terbanyak dengan jumlah tujuh belas kali berkokok dalam periode 1 dalam waktu 4.33.711 Menit dan pada periode 2 ayam dengan jumlah kokok terbanyak adalah ayam Bangkok dengan jumlah kokok 13,5 kali dalam waktu 3.03.902 menit. Hal ini berbeda dengan Ayam Kokok Balenggek (AKB) yang mampu berkokok sebanyak 8,08 kali dalam waktu 10 menit (Rusfidra, 2005). Puncak Berkokok ayam terjadi pada pagi hari dan akan menurun pada siang dan sore hari. Kenyataan tersebut sependapat dengan pendapat Lunberg dan Alatallo (1992) yang menyatakan bahwa puncak berkicau pada burung terjadi pada pagi hari dan cenderung turun pada siang dan sore hari. Contoh Wave Form Frekuensi berkokok ayam Birma 


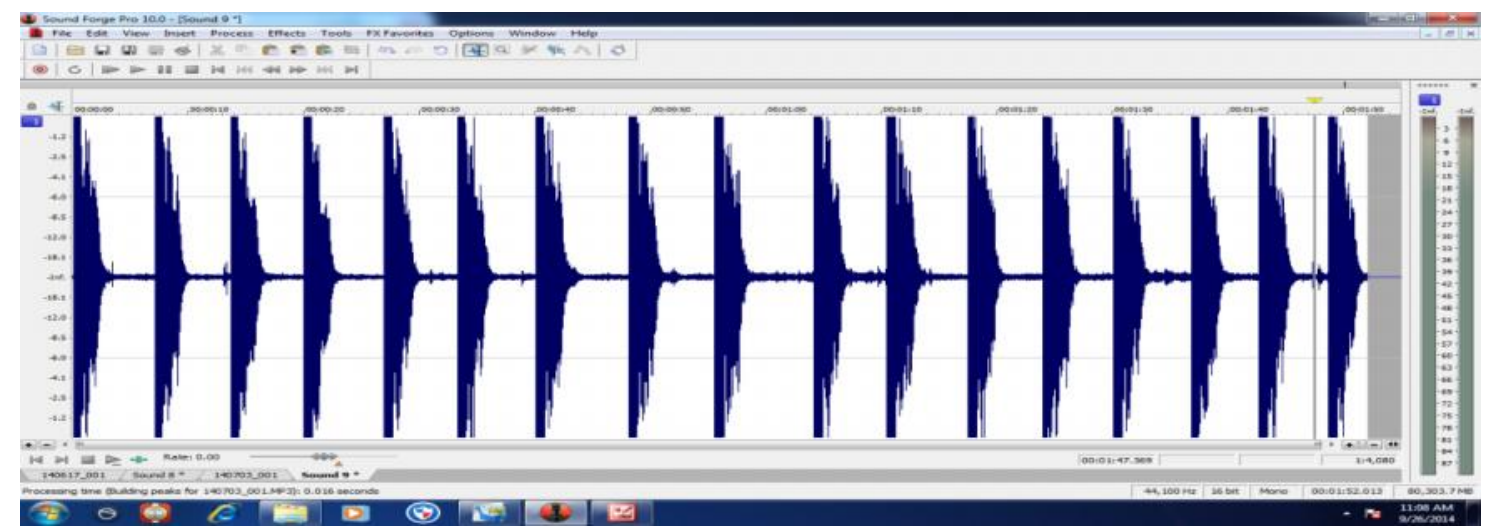

Gambar 4. Wave Form Frekuensi Berkokok Ayam Birma

Berdasarkan hasil analisis suara, dilakukan uji tambahan yaitu dengan melakukan uji $\mathrm{T}$ (T-Test) dengan Softaware Microsoft Excel. Dari hasil uji T untuk masing-masing parameter dalam Frekuensi berkokok didapat kesimpulan bahwa untuk jumlah berkokok periode 1, jumlah berkokok periode 2 dan Durasi jarak antara periode 1 dan periode 2 menunjukkann hasil yang Sangat Nyata. Hal ini sesuai dengan hasil perhitungan yang menghasilkan ( $\mathrm{t}$ hitung > t tabel). Pada parameter Durasi kokok periode 1 dan durasi kokok periode 2 menunjukkan hasil Berbeda nyata. Hal ini sesuai dengan perhitungan yang menghasilkan (t hitung < dari t tabel). Kesimpulan dari analisis Uji T adalah bahwa untuk jumlah berkokok periode 1 dan periode 2 dapat dijadikan tolak ukur dalam membedakan jenis ayam tersebut sesuai dengan bangsanya, sedangkan untuk durasi kokok 1 dan durasi kokok 2 tidak dapat dijadikan tolak ukur dalam membedakan jenis ayam. Contoh-contoh gambar pola gelombang suara dari ayam dengan frekuensi tertinggi ditampilkan pada Gambar 5-10.

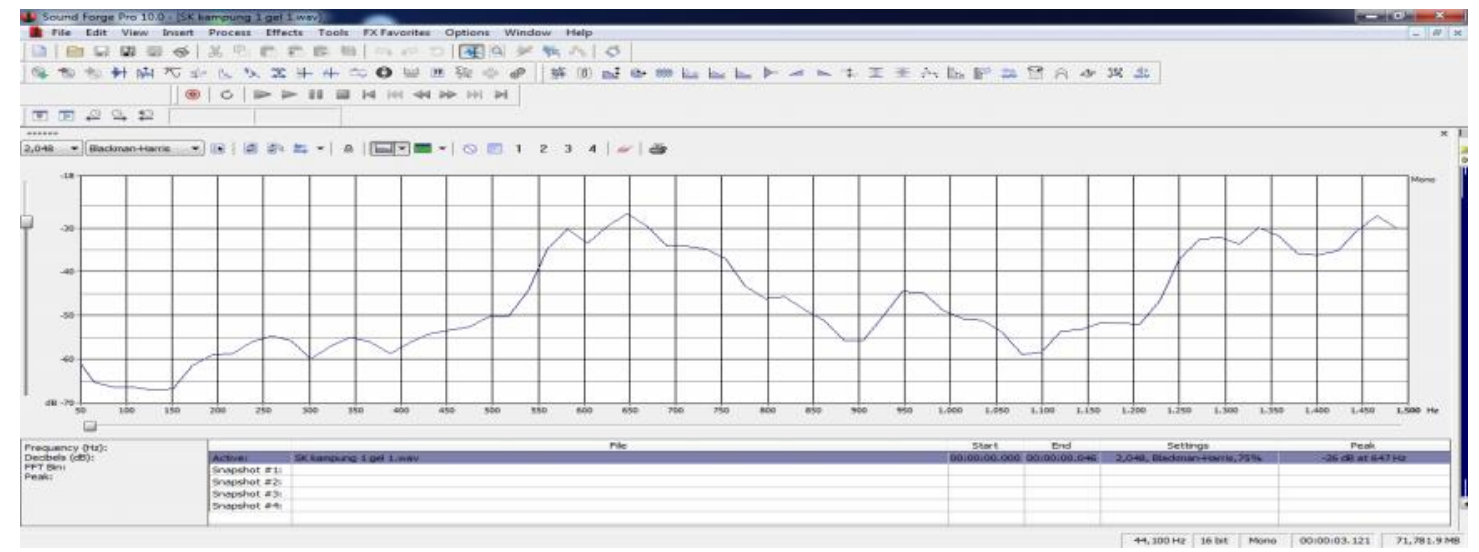

Gambar 5. Wave Form gelombang suara ayam Kampung 


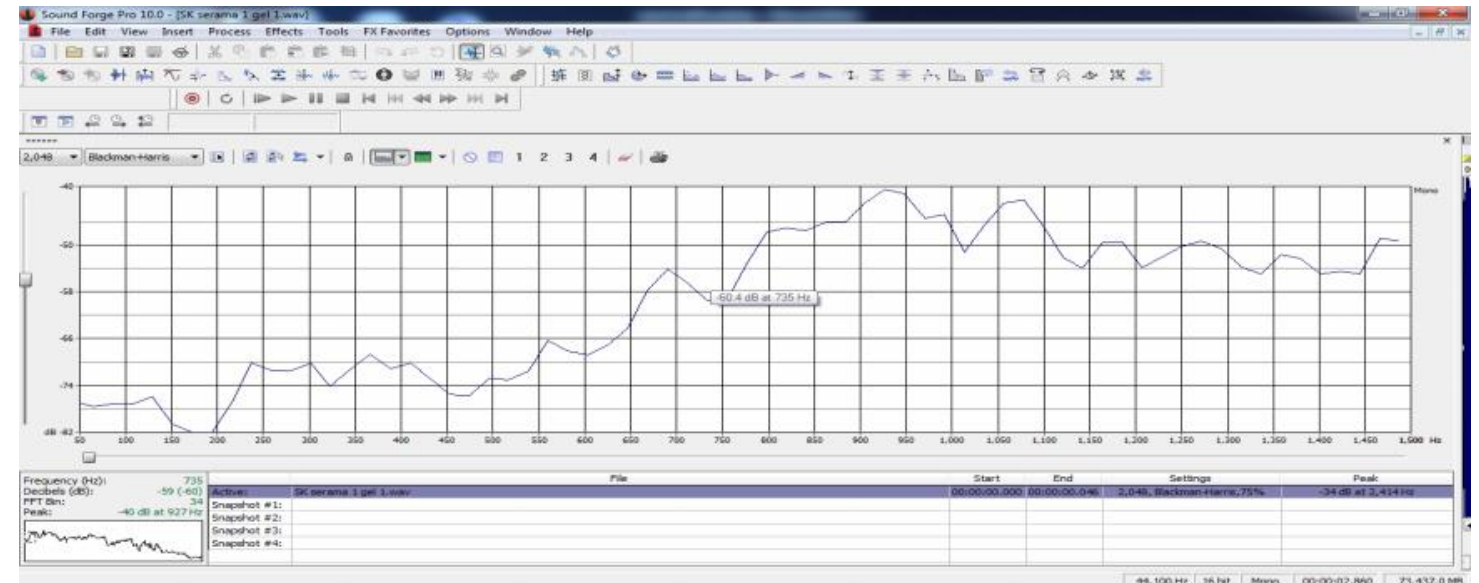

Gambar 6. Wave Form gelombang suara ayam Serama

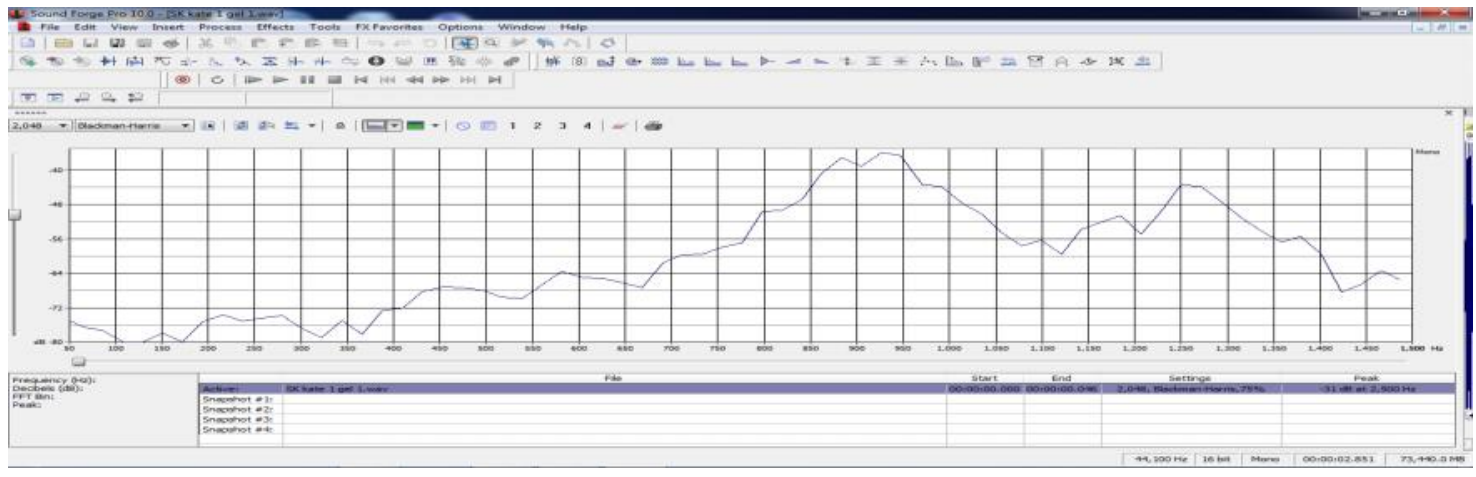

Gambar 7. Wave Form gelombang suara ayam Kate

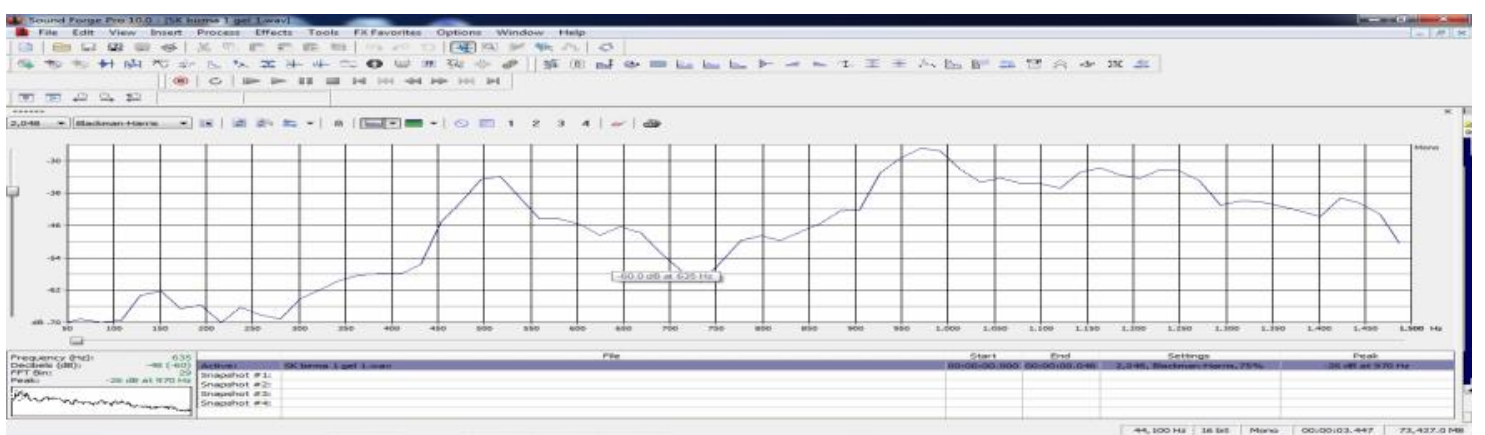

Gambar 8. Wave Form gelombang suara ayam Birma

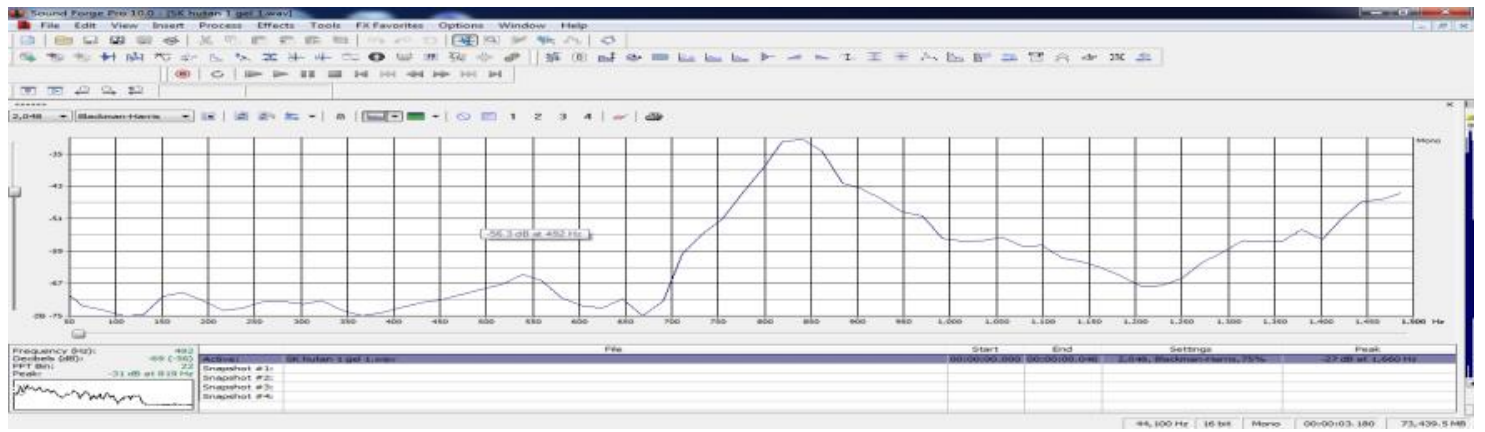

Gambar 9. Wave Form suara ayam Hutan 


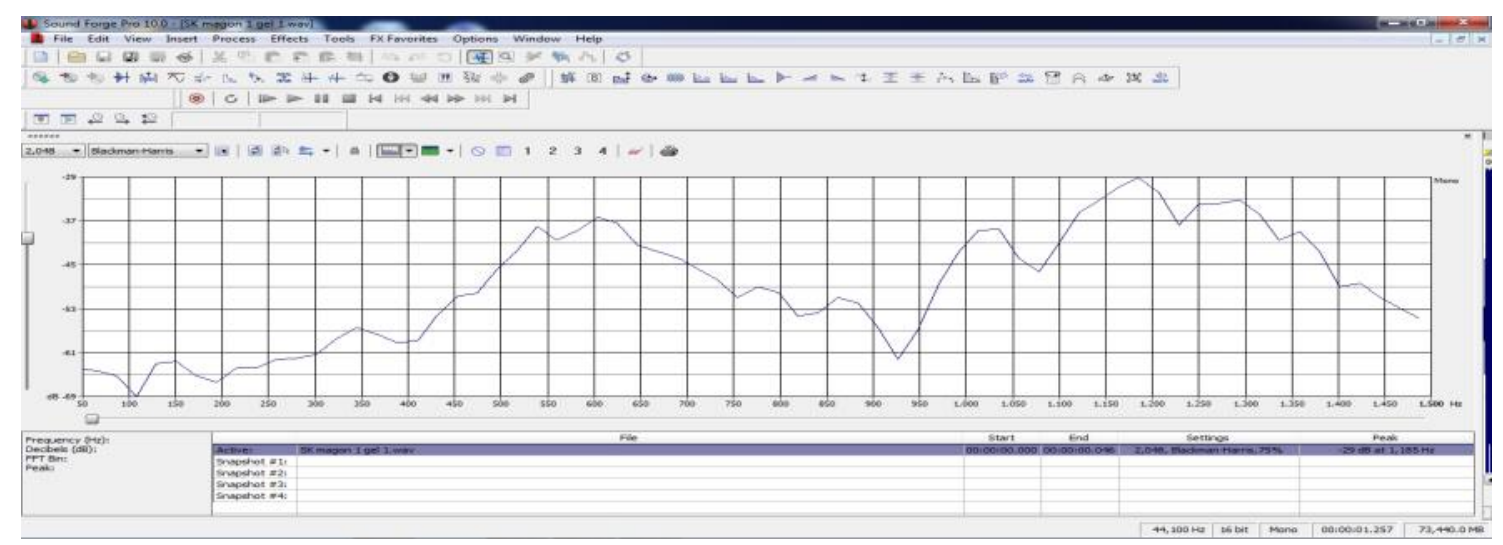

Gambar 10. Wave Form gelombang suara ayam Magon

\section{KESIMPULAN}

Berdasarkan analisis suara didapat durasi kokok terpanjang adalah jenis ayam Kampung dengan durasi kokok 3,659 detik dan yang tercepat adalah jenis ayam Magon dengan durasi 1,326 detik. Jumlah suku kata kokok pada ayam yang telah direkam didapat 10 jenis memiliki suku kata kokok sebanyak 4 suku kata dan 1 jenis memiliki suku kata 3 yaitu ayam Suratani.

Berdasarkan uji lanjut dengan menggunakan uji T didapat kesimpulan bahwa untuk jumlah berkokok periode 1 dan periode 2 dapat dijadikan tolak ukur dalam membedakan jenis ayam tersebut sesuai dengan bangsanya, sedangkan untuk durasi kokok 1 dan durasi kokok 2 tidak dapat dijadikan tolak ukur dalam membedakan jenis ayam.

Penggunaan Sound Forge xp 10 untuk menganalisis suara kokok ayam sangat berguna karena dapat menampilkan hasil yang detail dan terperinci. Untuk penelitian selanjutnya diharapkan agar menambah durasi untuk adaptasi ayam dengan lingkungan tempat perekaman untuk menghasilkan suara kokok yang lebih baik.

\section{DAFTAR PUSTAKA}

Anderson. 2010. Pengolahan suara melalui soundforge. http://wiaderko.net/id downloadprogramy/161322-sony-sound-forge-pro-10-0c-build-491-inclkeygen.html.http Diakses 23 maret 2014.

Anonimous. 2014. Keistimewaan Ayam Bangkok. Tersedia pada http://ayam-bangkokcom.blogspot.com. Diakses pada tanggal 17 Oktober 2014. 
Fredde M. R. 1976. Respiration. Di dalam: Sturkie PD. (ed.). 1976. Avian Phisichology Ed. ke-3. New York ,Heiderberg, Berlin: Springer-Verlag

Junaidi. 2012. Karakteristik Bioakustik dari 287 ekor ayam Gaga. Skripsi.Fakultas Peternakan Universitas Hasanuddin. Makassar.

Lunberg, A. and R. V. Alatalo. 1992. The Pied Flycatcher. T\&AD Poyser.

Nurningsih. 2010. Karakteristik Bioakustik Suara Ayam Buras Jantan Pada Umur Yang Berbeda. Skripsi. Fakultas Peternakan. Universitas Hasanuddin.

Oliver J. 1966. Kehidupan burung. Dalam: Ilmu Pengetahuan Populer Jilid 7. Jakarta. Groller International Inc - PT. Widyadara

Rukmini, S., dan Herawati, S. 2000. Teknik Pemeriksaan Telinga Hidung Tenggorokan, Penerbit Buku Kedokteran EGC, Jakarta.

Rusfidra. 2004. Karakterisasi sifat-sifat fenotipik sebagai strategi awal konservasi ayam Kokok Balenggek di Sumatera Barat. Disertasi. Bogor: Sekolah Pascasarjana IPB.

2005. Analisis suara kokok pada ayam Kokok Balenggek; ayam local berkokok merdu dari Sumatera Barat. Laporan Penelitian. Fakultas Peternakan Universitas Andalas Kampus UNAND Limau Manis, Padang.

---------. 2005. Kajian Bioakustik pada Ayam Balenggek Ayam Lokal Penyanyi Sumatera Barat. Laporan Penelitian. Universitas Andalas, Padang.

Sudjana. 2005. Metode Statistika. Edisi Ke-6. Tarsito. Bandung

Tzudzuki, M. 2003. Japanese Native Chickens. In: Chang, H, L., and Y. C. Huang .2003. The Relationship between Indigenous Animals and Humans in APEC Region. Chinese Taipe: The Chinese Society Anim, Sci, pp.91-116

Zymmerman P. 1995. Vocalisation as a welfare indicator in laying hens. 